\title{
Numerical Analysis through a Tubular Reactor: Velocity Effect
}

\author{
R. Nasrin \\ Department of Mathematics, Bangladesh University of Engineering \& Technology, Dhaka-1000, \\ Bangladesh
}

Email: raity11@gmail.com

\begin{abstract}
Chemical reactions occur everywhere in our everyday life, for example, in the human body, in cell phone batteries, in a rocket engine and in the pharmaceutical and chemical industry. In this research the model provides a study of an elementary, exothermic, 2nd-order reversible reaction in a tubular reactor (liquid phase, laminar flow regime). The aim of this project is to study numerically the effect of convective Heat and Mass transfer flow of a viscous fluid in the reactor. Assuming that the variations in angular direction around the central axis are negligible makes it possible to reduce the model to a $2 \mathrm{D}$ axisymmetric model. The investigation of forced convection flow, heat and mass transfer phenomena through a tubular reactor is carried. The implications of Reynolds number $(R e)$ and Prandtl number $(P r)$ on the flow structure, heat transfer and mass transfer characteristics are presented. The results are presented in the form of stream functions, isothermal lines, iso-concentrations, surface temperature, arrow plot, average Nusselt number and Sherwood number, mean temperature, average concentration and mean velocity.
\end{abstract}

Keywords: Tubular reactor, Numerical analysis, Finite element method, Velocity effect.

\section{INTRODUCTION}

Few researchers investigated the effects of forced convective flows in tubular chemical reactor by using analytical, experimental and numerical methods. Some important works are presented below.

Combined heat and mass transfer from a horizontal channel with an open cavity heated from below is numerically examined Brown and Lai [1]. Parvin et al. [2] analyzed numerically the effect of double-diffusive natural convection of a water- $\mathrm{Al}_{2} \mathrm{O}_{3}$ nanofluid in a partially heated enclosure with Soret and Dufour coefficients. Muthucumaraswamy and Ganesan [3] studied effect of the chemical reaction and injection on flow characteristics in an unsteady upward motion of an isothermal plate. Deka et al. [4] studied the effect of the first order homogeneous chemical reaction on the process of an unsteady flow past an infinite vertical plate with a constant heat and mass transfer. Chamkha [5] studied the MHD flow of a numerical of uniformly stretched vertical permeable surface in the presence of heat generation/absorption and a chemical reaction. He assumed that the plate is embedded in a uniform porous medium and moves with a constant velocity in the flow direction in the presence of a transverse magnetic field.

Ibrahim et al. [6] have studied the effect of chemical reaction and radiation absorption on the unsteady MHD free convection flow past a semi infinite vertical permeable moving plate with heat source and suction. Kesavaiah et al [7] have studied the effect of the chemical reaction and radiation absorption on an unsteady MHD convective heat and mass transfer flow past a semi-infinite vertical permeable moving plate embedded in a porous medium with heat source and suction. Heat and mass transport in tubular packed reactors at reacting and non-reacting conditions was analyzed by Koning [8] where the most common models of wallcooled tubular packed bed reactors were presented. The two dimensional axial plug flow model was used for a water gas shift reactor to compare heat conduction or mass diffusion with convective effect. Heat and mass transfer in tubular reactor is shown in [9-10]. The two dimensional axial plug flow model was used for a water gas shift reactor to compare heat conduction or mass diffusion with convective effect in his study.

The design of catalyst particles for fixed-bed reactor is optimized by computational fluid dynamics (CFD). The CFD is used to obtain detailed flow and temperature fields in the reactor. In the field of reactor engineering, physical demands such as low pressure drop or high heat transfer efficiency are often in conflict with chemical demands such as gas contact efficiency [11]. Low tube-to-particle diameter ratio is needed for heat management, i.e. sufficient heat supply from the reactor wall for highly endothermic reaction or sufficient heat removal to the reactor wall for highly exothermic reaction [12]. Steam reforming of hydrocarbons is one of the examples, which is an endothermic reaction [13], while another is $\mathrm{CO}$ combustion, which is an exothermic reaction.

The early stage of reactor modeling has been based on simplifying assumption such as homogeneity, effective 
transport parameters, and pellet effectiveness factors [14- 15]. Homogeneity stands for viewing the fixed-bed as a single phase continuum. The assumption of effective or apparent transport parameters is based on the idea of unidirectional axial plug flow of the fluid throughout the reactor. These effective transport parameters are determined empirically, i.e. the parameters lump together all of the contributing physical phenomena. This assumption is still employed frequently in reactor modeling [16-18]. However, this approach has always caused inconsistency in the heat transfer coefficient or wall Nusselt number among a number of reported results. The inconsistency is originated from the lack of the local-scale flow picture of the bed. Recent magnetic resonance imaging (MRI) [19] have demonstrated that heat is transferred not solely by axial flow but also by strong radial convective flows as fluid is displaced around the packing elements.

Masoumi et al. [20] developed a 1D steady-state model for tubular reactors in naphtha cracking. A free-radical reaction scheme including 90 species and 543 reactions was used. An optimization study was performed with the aim to maximize operating. Computational techniques for fluid flow have recently employed for reactor modeling as a alternative method to the above mentioned semi-empirical method, in attempting to understand detailed flow in the pore scale. The approach was validated by comparing apparent transport parameters with those from model-matching theory based on experimental measurements [21-22]. One of the outcomes of CFD is a complex picture of strong radial flow. Local heat transfer rates were shown not to be correlated statistically with the local flow field [23]. The pressure and the wall temperature were found to have little or no influence on the apparent heat transfer parameters [24]. One of the concerns in CFD is that all elements have a finite dimension in all edges, which does not allow actual contact points between solid parts. This limitation causes inconsistency of heat transfer coefficient with the one calculated by model-matching theory. To avoid this, the diameter of the particles was slightly reduced in the model and finer mesh density was applied to wall-particle and particle-particle contact regions [25]. Very recently, semi-empirical relation for forced convective analysis through a solar collector was studied by Nasrin [26]. Mabood et al. [27] analyzed non-uniform heat source/sink and soret effects on MHD non- Darcian convective flow past a stretching sheet in a micropolar fluid with radiation

In the light of above discussions, it is seen that there has been a good number of works in the field of heat and mass transfer system through chemical reactor. In spite of that there is some scope to work with fluid flow, heat-mass transfer and enhancement of reactor efficiency specially for tubular reactor. Therefore the analysis of the heat-mass transfer through a tubular reactor is necessary to ensure better performance of production.

\section{PHYSICAL MODEL}

The model geometry of tubular reactor is given in the figure 1. This model consists of an inlet boundary, an outlet boundary, a reactor wall facing the cooling jacket, a cooling jacket, and a symmetry line running axially along the tubular reactor.

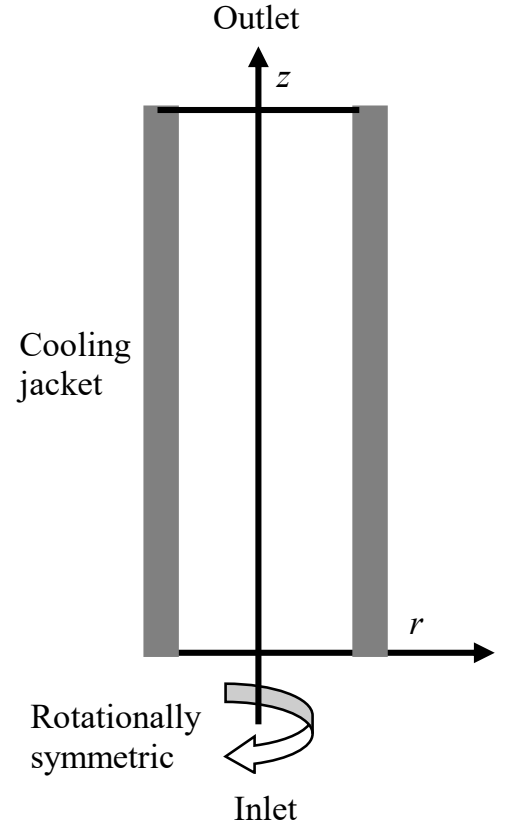

Figure 1. 2D rotationally symmetric model of tubular reactor

Assuming that the variations in angular direction around the central axis are negligible makes it possible to reduce the model to a 2D axisymmetric model. A schematic diagram of the system considered in the present research is shown in the figure 2. In this study, an axial two dimensional tubular reactor model is built up numerically using software. $L$ and $R_{a}$ are the length and radius of the reactor. Only steady state case is considered.

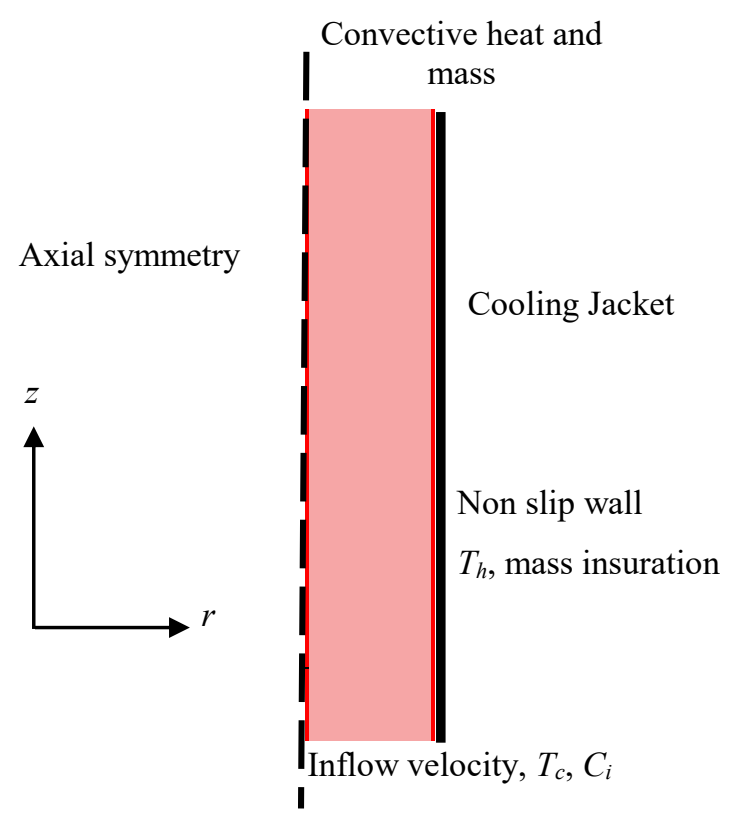

Figure 2. Schematic diagram of the tubular reactor

\section{MATHEMATICAL MODEL}

The reactor is equipped with a cooling jacket to limit the temperature increase due to the exothermic nature of the reaction and avoid an explosion. The model is described by the mass and momentum balances for the laminar flow region, material balances for the species involved and the energy balances for the reactor and the cooling jacket. 
Assuming that the diffusivity for the three species is identical, the reactor can be modeled using six differential equations; one mass balance and two momentum balances for laminar flow, one material balance for one of the species, one energy balance for the reactor core, and one energy balance for the heating jacket. Due to rotational symmetry, only the solution of these equations is obtained for half of the domain shown in figure 2.

The mass balance, momentum balances, material balances and energy balances in the tubular reactor can be represented with partial differential equations (PDEs), while one ordinary differential equation (ODE) is required for the energy balance in the cooling jacket.

The material balance and the energy balance in the reactor are defined in the governing equations while the ordinary differential equation describes the energy balance in the cooling jacket is defined as a boundary equation.

The mass, momentum, energy and material balances for the tubular reactor can be described by:

$$
\begin{aligned}
& \frac{1}{r} \frac{\partial\left(r v_{r}\right)}{\partial r}+\frac{\partial\left(v_{z}\right)}{\partial z}=0 \\
& \rho\left\{\frac{1}{r} \frac{\partial}{\partial r}\left(r v_{r} v_{r}\right)+\frac{\partial}{\partial z}\left(r v_{z} v_{r}\right)\right\}=-\frac{\partial p}{\partial r}+ \\
& \mu\left\{\frac{2}{r} \frac{\partial}{\partial r}\left(r \frac{\partial v_{r}}{\partial r}\right)+\frac{\partial}{\partial z}\left(r \frac{\partial v_{r}}{\partial z}\right)-2 \frac{v_{r}}{r^{2}}+\frac{\partial}{\partial z}\left(\frac{\partial v_{z}}{\partial r}\right)\right\}
\end{aligned}
$$$$
\rho\left\{\frac{1}{r} \frac{\partial}{\partial r}\left(r v_{r} v_{z}\right)+\frac{\partial}{\partial z}\left(r v_{z} v_{z}\right)\right\}=-\frac{\partial p}{\partial z}+
$$$$
\mu\left\{\frac{1}{r} \frac{\partial}{\partial r}\left(r \frac{\partial v_{z}}{\partial r}\right)+2 \frac{\partial}{\partial z}\left(\frac{\partial v_{z}}{\partial z}\right)+\frac{1}{r} \frac{\partial}{\partial r}\left(r \frac{\partial v_{r}}{\partial z}\right)\right\}
$$$$
\rho C_{p}\left\{v_{r} \frac{\partial T}{\partial r}+v_{z} \frac{\partial T}{\partial z}\right\}=k\left\{\frac{\partial}{\partial z}\left(\frac{\partial T}{\partial z}\right)+\frac{1}{r} \frac{\partial}{\partial r}\left(r \frac{\partial T}{\partial r}\right)\right\}
$$$$
+\left(\sum_{j}-\Delta H_{r, j}\right)\left(A e^{\frac{-E_{a}}{G_{c} T}}\right)
$$

$$
\begin{array}{r}
\rho C_{p}\left\{v_{r} \frac{\partial c}{\partial r}+v_{z} \frac{\partial c}{\partial z}\right\}=k\left\{\frac{\partial}{\partial z}\left(\frac{\partial c}{\partial z}\right)+\frac{1}{r} \frac{\partial}{\partial r}\left(r \frac{\partial c}{\partial r}\right)\right\} \\
-A e^{-\left(\frac{E_{a}}{G_{c} T}\right)}
\end{array}
$$

Here $R=-A \exp \left(-\frac{E_{a}}{G_{c} T}\right)$ is the rate of reaction, $H=\left(\sum_{j}-\Delta H_{r, j}\right)\left(A e^{\frac{-E_{a}}{G_{c} T}}\right)$ is the heat of reaction, $\operatorname{Pr}=\frac{v}{\alpha}$ is Prandtl number, $\operatorname{Re}=\frac{v_{i n} L}{v}$ is the Reynolds number.

The boundary condition also simulated the actual reaction condition. Figure 2 shows the boundary conditions for velocity, temperature, and $\mathrm{CO}$ concentration. The inlet gas composition was set to $13 \% \mathrm{CO}-8 \% \mathrm{CO}_{2}-28 \% \mathrm{H}_{2} \mathrm{O}-51 \%$ $\mathrm{H}_{2}$, which corresponds to $2.542 \mathrm{~mol} / \mathrm{m}^{3}$ of $\mathrm{CO}$ concentration. The fluid velocity at inlet is assumed laminar flow with average velocity of $0.085 \mathrm{~m} / \mathrm{s}$.

The boundary conditions are: at the inlet: $v_{r}=0, v_{z}=v_{i n}, T=T_{i n}, c=C_{i n}$ at the outlet: convective heat and mass boundary condition at the right wall: non slip condition, $T=T_{h}$, mass insuration condition

at the left wall: axial symmetry condition.

Only axial temperature variations may present in the cooling jacket and the flow eliminates any temperature differences in the radial direction. This assumption gives a single ODE for the energy balance:

$\frac{\partial T_{a}}{\partial z}=\frac{2 \pi R_{a} U_{k}\left(T-T_{a}\right)}{m_{c} C_{p c}}$

where $T_{a}$ is the coolants' temperature, $m_{c}$ is the mass flow rate of the coolant, $C_{p c}$ represents its heat capacity, and $U_{k}$ is the total heat-transfer coefficient between the reactor and the cooling jacket.

The contribution of heat conduction in the cooling jacket is neglected and thus it is assumed that heat transport takes place only through convection. As a boundary condition the temperature of the incoming cooling fluid: $T_{a}(0)=T_{a 0}$.

The average Nusselt number $(\mathrm{Nu})$ is expected to depend on a number of factors such as thermal conductivity, heat capacitance, viscosity and flow structure. The rate of heat transfer along the right heated wall of the tubular reactor is $N u=-\frac{1}{S} \int_{0}^{S} \frac{\partial \theta}{\partial r^{\prime}} d z^{\prime}$ and rate of mass transfer along the inlet opening is $S h=-\frac{1}{S} \int_{0}^{S} \frac{\partial C}{\partial z^{\prime}} d r^{\prime}$

where $S$ is the non-dimensional length of the heated/contaminant surface. Non-dimensional quantities are:

$$
\begin{aligned}
& r^{\prime}=\frac{r}{L}, \quad z^{\prime}=\frac{z}{L}, \quad V_{r}=\frac{v_{r}}{V_{i n}}, \quad V_{z}=\frac{v_{z}}{V_{i n}}, \\
& \theta=\frac{\left(T-T_{i n}\right)}{\Delta T}, C=\frac{\left(c-C_{i n}\right)}{\Delta c}
\end{aligned}
$$

The mean bulk temperature, concentration and magnitude of sub domain velocity of the fluid inside the tubular reactor can be written as $\theta_{a v}=\int \theta d \bar{V} / \bar{V}, \quad C_{a v}=\int C d \bar{V} / \bar{V}$ and $V_{a v}=\int V d \bar{V} / \bar{V}$, where $\bar{V}$ is the volume of the riser pipe of a flat plate solar collector.

\section{COMPUTATIONAL PROCEDURE}

The governing equations along with the boundary conditions are solved numerically, employing Galerkin weighted residual finite element techniques. To derive the finite element equations, the method of weighted residuals Zienkiewicz [28] is applied to the governing equations (1) (5). Gauss's Divergence theorem is applied to transfer the $2^{\text {nd }}$ ordered derivative part of the governing equations into $1^{\text {st }}$ order derivatives. Gaussian quadrature technique is used in momentum, energy and concentration equations in order to generate the boundary integral terms associated with the surface tractions, heat flux and concentration flux. The basic unknowns for the above differential equations are the velocity components $u_{r}, u_{z}$, the temperature $T$, the concentration $c$ and the pressure $p$. The six node triangular element is used in this 
work for the development of the finite element equations. All six nodes are associated with velocities, temperature as well as concentration. Only the corner nodes are associated with pressure. This means that a lower order polynomial is chosen for pressure and which is satisfied through continuity equation. The Galerkin finite element method is used to solve velocity components, the temperature distribution, the concentration distribution and linear interpolation for the pressure distribution according to their highest derivative orders. These element matrices are evaluated in closed form ready for numerical simulation. Substituting the element velocity components, the temperature, the concentration and the pressure distributions to the governing equations the linear algebraic equations are obtained. Then the equations are solved by applying the Newton-Raphson iteration technique. This leads to a set of algebraic equations with the incremental unknowns of the element nodal velocity components, temperatures, concentration and pressures. The iteration process is terminated if the percentage of the overall change compared to the previous iteration is less than the specified value. To solve the sets of the global nonlinear algebraic equations in the form of matrix, the NewtonRaphson iteration technique has been adapted through PDE solver with MATLAB interface. The convergence of solutions is assumed when the relative error for each variable between consecutive iterations is recorded below the convergence criterion $\varepsilon$ such that $\left|\Psi^{n+1}-\Psi^{n}\right|<\varepsilon$, where $n$ is number of iteration and $\Psi=v_{r}, v_{z}, T, c$ and $p$. The convergence criterion was set to $\varepsilon=10^{-6}$.

\subsection{Meshing}

In the finite element method, the mesh generation is the technique to subdivide a domain into a set of sub-domains, called finite elements, control volume, etc. The discrete locations are defined by the numerical grid, at which the variables are to be calculated. It is basically a discrete representation of the geometric domain on which the problem is to be solved. The computational domains with irregular geometries by a collection of finite elements make the method a valuable practical tool for the solution of boundary value problems arising in various fields of engineering. Figure 3 displays the finite element mesh of the present physical domain.

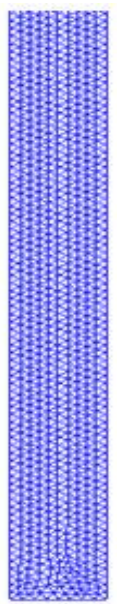

Figure 3. Mesh generation of the tubular reactor

\subsection{Grid Test}

An extensive mesh testing procedure is conducted to guarantee a grid-independent solution for $\operatorname{Pr}=7, R=1, H=$ 1 and $R e=1.5$ through the tubular reactor. In the present work, five different non-uniform grid systems are examined with the following number of elements within the resolution field: $60,240,960,3840$ and 15360 . The numerical scheme is carried out for highly precise key in the $N u$ and $S h$ for the aforesaid elements to develop an understanding of the grid fineness as shown in Table 1. The scale of the average Nusselt and Sherwood numbers for 3840 elements shows a little difference with the results obtained for the other elements. Hence, considering the non-uniform grid system of 3840 elements is preferred for the computation.

Table 1. Grid Test at $\operatorname{Pr}=7, R=1, H=1$ and $R e=1.5$

\begin{tabular}{|l|l|l|l|l|l|}
\hline Elements & 60 & 240 & 960 & 3840 & 15360 \\
\hline $\mathrm{Nu}$ & 6.82945 & 7.23842 & 7.72141 & 8.00183 & 8.00206 \\
\hline $\mathrm{Sh}$ & 0.53256 & 0.71475 & 0.92181 & 1.10204 & 1.10275 \\
\hline Time (s) & 127.52 & 308.75 & 581.11 & 897.23 & 1295.31 \\
\hline
\end{tabular}

\section{RESULTS AND DISCUSSIONS}

Finite element simulation is applied to perform the analysis of laminar forced convection temperature, fluid flow, concentration through a tubular chemical reactor. Effects of the Reynolds number $(R e)$ and Prandtl number $(P r)$ on heatmass transfer, fluid velocity through the tubular reactor have been studied. The ranges of $R e$ and $P r$ for this investigation vary from 0.1 to 2 and 0.73 to 7 respectively where rate of reaction $\left(R=1 \mathrm{~mol} / \mathrm{m}^{3} / \mathrm{s}\right)$ and heat of reaction $(H=1 \mathrm{~kJ} / \mathrm{mol})$. The outcomes for the different cases are presented in the following sections.

\subsection{Effect of Reynolds Number}

It is of interest to note that both temperature and concentration develop in a similar way. As in figure 4(c), isoconcentration lines have great change due to Reynolds number variation from 0.1 to 2 . Besides, an increase in the value of $R e$, leads to denser iso-concentration lines because of the dominating behavior of inertia force. Thus the isoconcentration lines concentrate at the right surface for $R e=2$. It is also seen from the figure that, the lower concentration lines remain at the right boundary where as the higher concentration lines at the input boundary.

From the figure 4(d), it is observed that there is a common trend of the evolution of streamlines with increasing Reynolds numbers. The streamlines are parallel to the tubular reactor wall and condensed near the axial symmetry boundary. The red and blue colors indicate the streamlines with high and low strength respectively. This happens because of higher thermal buoyancy effect.

On the other hand, in the profile of arrow plot, the arrow strength is low at the lowest value of $R e$. The arrow strength increases through the tubular chemical reactor due to increase inertia force from 0.1 to 2 .

Finally, the arrow plots illustrate that inertia force dominant effect plays a critical role on larger fluid flow from inlet opening to the passing fluid through the outlet exit. Arrow 
plots also show that there is a clear difference in the fluid flow trajectory for the influence of inertia force. This difference is largely attributed for $R e=2$ within the system.

$R e=0.1 \quad R e=1 \quad R e=1.5 \quad R e=2 \quad R e=0.1 \quad R e=1 \quad R e=1.5 \quad R e=2$

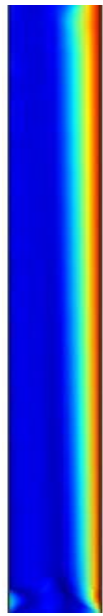

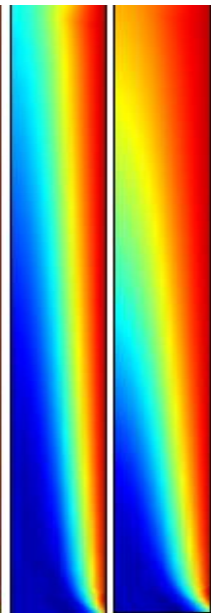

(a)

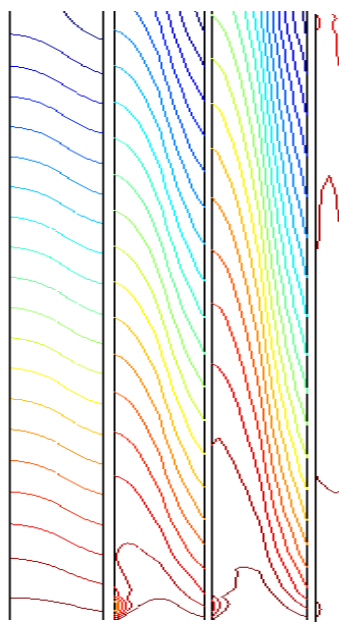

(c)
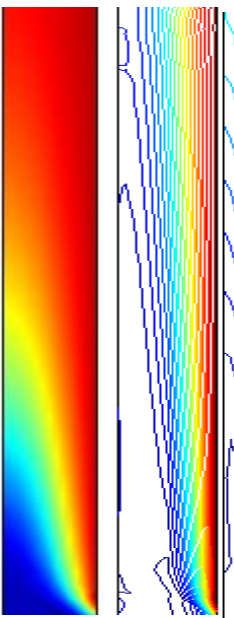

(an
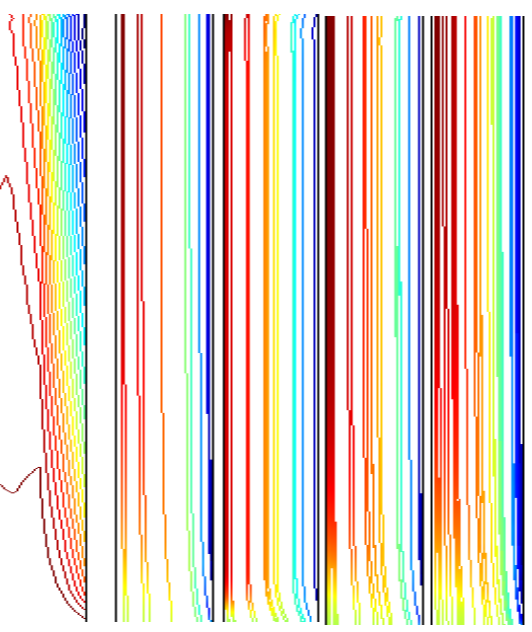

(d)

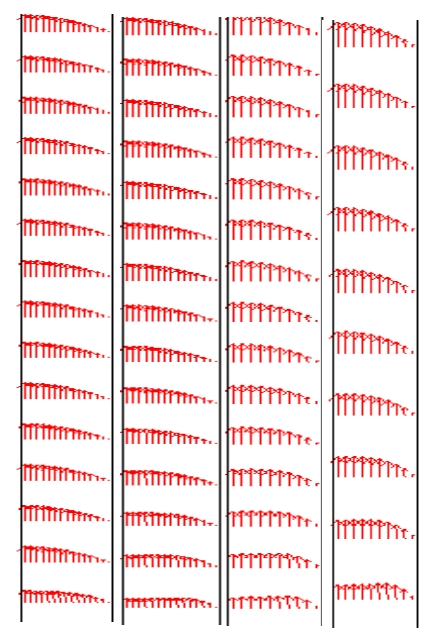

(e)

Figure 4. Effect of Re on (a) surface plot and (b) isotherms, (c) iso-concentration, (d) streamlines and (e) arrow plot

The $N u$-Re, Sh-Re, $\theta_{a v}-R e, C_{a v}-R e$ and $\mathrm{V}_{\mathrm{av}}-R e$ profiles for fluid are depicted in the figure $5(\mathrm{i})-(\mathrm{v})$. It is seen from the figure 5(i-ii) that average Nusselt number $(\mathrm{Nu})$ and Sherwood number $(S h)$ forms parabolic shape with mounting Reynolds number. The rates of forced convective heat transfer and mass transfer enhance $31 \%$ and $29 \%$ respectively for rising inertia force from 0.1 to 2. Figure 5(iii-iv) displays mean temperature $\left(\theta_{a v}\right)$ and mean concentration $\left(C_{a v}\right)$ falls sequentially for all $R e$. Magnitude of average velocity vector $\left(\mathrm{V}_{\mathrm{av}}\right)$ for the effect of Reynolds has notable changes with different values of inertia forces. It is observed that the average velocity increases through the tubular chemical reactor due to the increase in the Reynolds number because of higher values of forced convection.

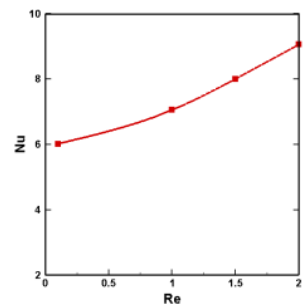

(i)

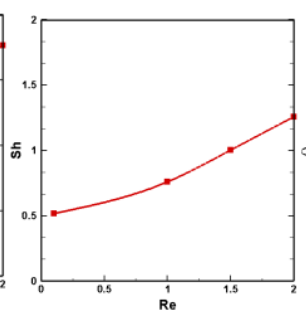

(ii)

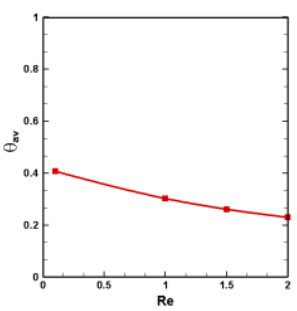

(iii)

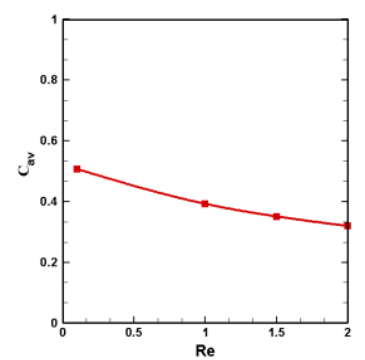

(iv)

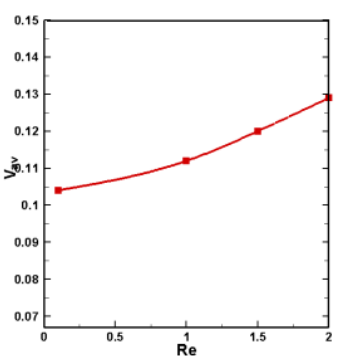

(v)
Figure 5. Effect of Re on (i) mean Nusselt number, (ii) mean Sherwood number, (iii) mean temperature, (iv) mean concentration and (v) mean velocity

\subsection{Effect of Prandtl Number}

Figure 6 (a) - (d) represents the effect of $P r$ on the surface temperature, isothermal lines, iso-concentration lines and streamlines distributions while $R e=1.5, H=1 \mathrm{~kJ} / \mathrm{mol}$ and $R$ $=1 \mathrm{~mol} / \mathrm{m}^{3} / \mathrm{s}$. The values of Prandtl number are taken as 0.73 , 1.73, 3 and 7. Different values of Prandtl number represent different types of fluid at different temperatures.

The surface temperature in figure 6(a) clearly shows higher magnitude for heat transfer due to $\mathrm{Pr}=7$ compared to other values of $P r$ as seen from the surface temperature pattern. Different colors are observed for surface temperature profile near the core and this illustrates a larger magnitude of conductive heat transfer. The fluid through the tubular reactor receives most of the heat from the hot walls. But, the presence of blue color in surface temperature at $P r=0.73$ does not contribute to higher heat transfer compared to the other values of Prandtl number. Due to the growing $P r$ the color of surface temperature changes from blue (lowest temperature) to red (highest temperature) for the optimum heat transfer from heated surfaces to the fluid through the exit port of the pipe.

Isotherms are almost similar to the active parts of tubular reactor. Increasing $\mathrm{Pr}$, the temperature lines at the middle part of the riser pipe become more bended whereas initially they are almost wavy pattern due to viscosity is dominated across the tubular reactor. With rising values of $\operatorname{Pr}$ from 0.73 to 7 , the temperature distributions become distorted resulting in an 
increase in the overall heat transfer. This result can be attributed to the dominance of the viscous force. It is worth noting that as the Prandtl number increases, the thickness of the thermal boundary layer near the input surfaces rises which indicates a steep temperature gradients and hence, an increase in the overall heat transfer from the hot walls to the fluid through the fluid passing region.

$$
\operatorname{Pr}=0.73 \operatorname{Pr}=1.73 \operatorname{Pr}=3 \operatorname{Pr}=7 \operatorname{Pr}=0.73 \operatorname{Pr}=1.73 \operatorname{Pr}=3 \operatorname{Pr}=7
$$

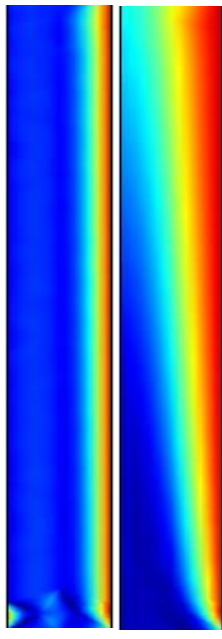

(a)

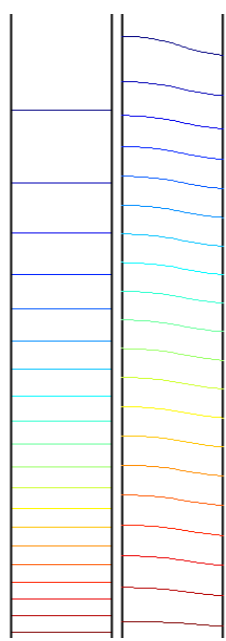

(c)
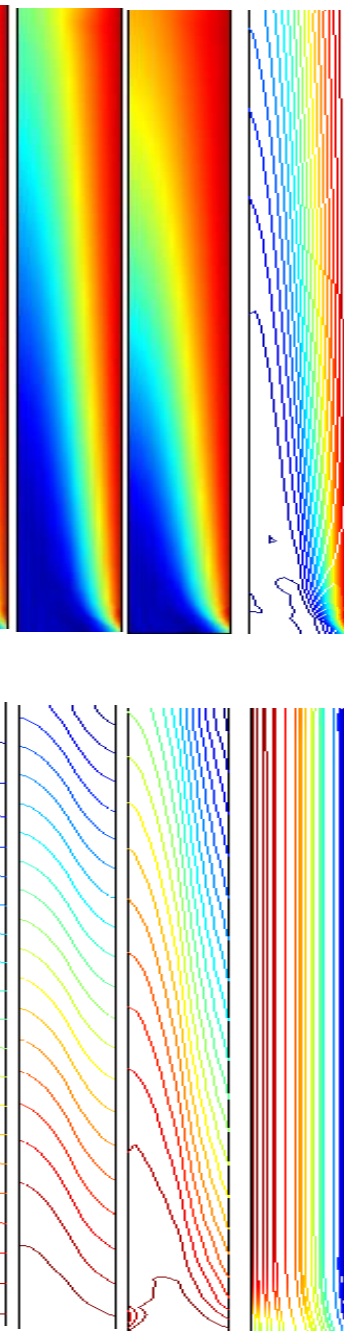

Figure 6. Effect of $\operatorname{Pr}$ on (a) surface plot and (b) isotherms, (c) iso-concentration and (d) streamlines

It is observed from the figure 6(c) that the iso-concentration lines are not dense near the solid surfaces due to viscosity dominant mass transfer. The viscous mass transfer facilitates thermal mixing leading to high concentration gradient at the core as the dense iso-concentration lines are observed near the input and output surfaces. Deformation of isoconcentration lines near the inlet is observed, showing the presence of viscous effect in the system. However, the concentration mixing near the core is not intense due to lower mass flow for $\mathrm{Pr}=0.73$. Overall, larger mass may be recovered through the tubular reactor for fluid with greater $\operatorname{Pr}$.

The streamlines occupying the whole pipe is found at the lowest value of Prandtl number $(P r=0.73)$. Then the velocity of the fluid reduces with the deviation of $P r$. This happens due to fluid with greater velocity indicates lower Prandtl number. Otherwise there is no significant change in the streamlines observed. Number of streamlines becomes lower due to rising Prandtl number.

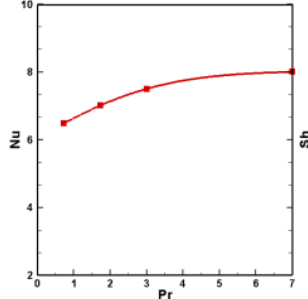

(i)

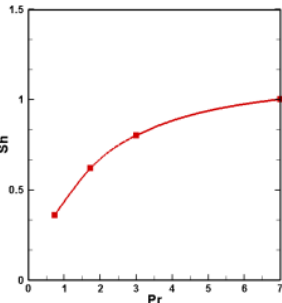

(ii)

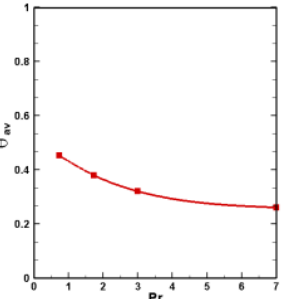

(iii)

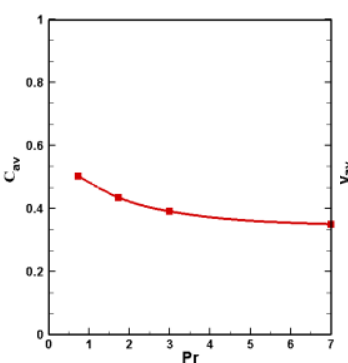

(iv)

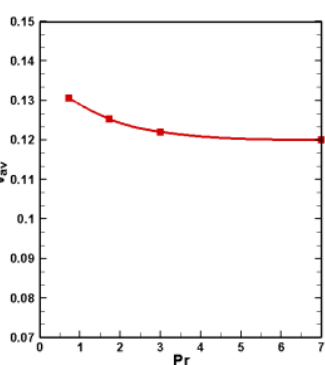

(v)
Figure 7. Effect of $P r$ on (i) mean Nusselt number, (ii) mean Sherwood number, (iii) mean temperature, (iv) mean concentration and (v) mean velocity

The effect of Prandtl number on average Nusselt and Sherwood numbers, mean bulk temperature and concentration, average sub-domain velocity of fluid are expressed in the figure 7(i)-(v). Figure 7(i-ii) shows that heat transfer rate $(\mathrm{Nu})$ and mass transfer rate $(S h)$ enhances with growing $P r$. The rates of heat and mass transfer rise for fluid is found to be by $23 \%$ and $20 \%$ with increasing values of $P r$. Consequently, mean temperature $\left(\theta_{a v}\right)$ along with the Prandtl number falls sequentially. It is well known that higher values of $\mathrm{Pr}$ indicate lower temperature of fluids. Average concentration $\left(C_{a v}\right)$ also goes down for growing Prandl number $(P r)$. From the figure $7(\mathrm{v})$ it is seen that magnitude of mean velocity $\left(\mathrm{V}_{\mathrm{av}}\right)$ has notable changes with different values of viscous forces. It is well known that velocity of higher viscous fluid is less than that of lower viscous fluid. Falling viscous force enhance the mean velocity of the fluid through the tubular chemical reactor.

\section{CONCLUSIONS}

A finite element method is used to make the present investigation for steady-state, incompressible, laminar and forced convective flow in a tubular reactor. The major conclusions have been drawn as follows:

- The forced convection parameter $R e$ has a significant effect on the temperature, flow and heat flux fields. Thermal layer near the heated surface becomes thick, number of streamlines is increased and most of isoconcentration lines changes their shape from curve to almost flat with increasing $R e$. Heat transfer rate and mean velocity rise but mean temperature of both type of fluids decreases for this velocity effect.

- The influence of Prandtl number on surface temperature, streamfunction, isotherms and iso-concentration are remarkable. The thermal boundary layer develops near the solid surfaces with elevating $P r$. Due to rising $P r$ collector efficiency and mid-height temperature diminish. 


\section{ACKNOWLEDGEMENT}

This research work is done in the Department of Mathematics, Bangladesh University of Engineering \& Technology, Dhaka-1000. This research is financed by Information \& Communication Technology, Ministry of Science, Bangladesh Computer Council Bhaban, Agargaon, Sher-e-Bangla Nagar, Dhaka-1207.

\section{REFERENCES}

[1] Brown, N. and Lai, F., "Correlations for combined heat and mass transfer from an open cavity in a horizontal channel," Int. Commun. in Heat and Mass Transf., vol. 32, no. 8, pp. 1000-1008, 2005. DOI: 10.1016/j.icheatmasstransfer.2004.10.029.

[2] Parvin S., Nasrin R., Alim, M. A. and Hossain, N. F., "Double-diffusive natural convection in a partially heated enclosure using a nanofluid," Heat Transf. Asian Res., vol. 41, no. 6, pp 484-497, 2012. DOI: 10.1002/htj.21010.

[3] Muthucumaraswamy, R. and Ganesan, P., "Effect of the chemical reaction and injection on flow characteristics in an unsteady upward motion of an isothermal plate," J. Appl. Mech. Tech. Phys., vol. 42, pp. 665-671, 2001.

[4] Das, U. N., Deka, R. and Soundalgekar, V.M., "Effects of mass transfer on flow past an impulsively started infinite vertical plate with constant heat flux and chemical reaction," Forsch. in Ingenieurw., vol. 60, pp. 284-287, 1994.

[5] Chamka, A. J., "MHD flow of a numerical of uniformly stretched vertical permeable surface in the presence of heat generation/absorption and a chemical reaction," Int. Commun. In Heat and Mass Transf., vol. 30, pp. 413-22, 2003.

[6] Ibrahim, F. S., Elaiw, A. M. and Bakr, A. A., "Effect of chemical reaction and radiation absorption on the unsteady MHD free convection flow past a semiinfinite vertical permeable moving plate with heat source and suction," Comm. in Nonlinear Sci. and Num. Simul., vol. 13, pp. 1056-1066, 2008. DOI: 10.1016/j.cnsns.2006.09.007.

[7] Kesavaiah, D.C.H., Satyanarayana, P.V. and Venkataramana, S., "Effects of the chemical reaction and radiation absorption on an unsteady MHD convective heat and mass transfer flow past a semiinfinite vertical permeable moving plate embedded in a porous medium with heat source and suction," Int. J. of Appl. Math. and Mech., vol. 7, no. 1, pp. 52-69, 2011.

[8] Koning, B., "Heat and mass transport in tubular packed bed reactors at reacting and non-reacting conditions," Ph.D. Thesis, University of Twente, Netherland, 2002.

[9] Kugai, J., "Heat and mass transfer in fixed-bed tubular reactor," May $1^{\text {st }}, 2008$.

[10] Frolov, S. V., Tret'yakov, A. A. and Nazarov, V. N., "Problem of optimal control of monomethylaniline synthesis in a tubular reactor," Theore. Found. of Chem. Engg., vol. 40, no. 4, pp. 349-356, 2006. DOI: 10.1134/S0040579506040038.

[11] Nijemeisland, M., Dixon, A. G. and Stitt, E. H., "Catalyst design by CFD for heat transfer and reaction in steam reforming," Chem. Engg. Sci., vol. 59, pp. 5185-5191, 2004. DOI: 10.1016/j.ces.2004.07.088.

[12] Rostrup-Nielsen, J. R., Sehested, J. and Norskov, J. K., "Hydrogen and synthesis gas by steam- and $\mathrm{CO}_{2}$ reforming," Adv. Catal., vol. 47, pp. 65-139, 2002. DOI: $\underline{10.1002 / \text { chin.200317288 }}$

[13] Kvamsdal, H. M., Svendsen, H. F., Hertzberg, T. and Olsvik, O., "Dynamic simulation and optimization of a catalytic steam reformer," Chem. Engg. Sci., vol. 54, pp. 2697-2706, 1999. DOI: 10.1016/S00092509(98)00329-7.

[14] Dixon, A. G. and Nijemeisland, M., "CFD as a design tool for fixed-bed reactors," Ind. Engg. Chem. Res., vol. 40, pp. 5246-5254, 2001. DOI: 10.1021/ie001035a.

[15] Dixon, A. G. and Cresswell, D. L., "Theoretical prediction of effective heat-transfer parameters in packed-beds," Aiche. J., vol. 25, pp. 663-676, 1979. DOI: $10.1002 /$ aic.690250413.

[16] Bunnell, D. G., Irvin, H. B., Olson, R. W. and Smith, J.M., "Effective thermal conductivities in gas-solid systems," Ind. Engg. Chem., vol. 41, pp. 1977-1981, 1949. DOI: $10.1021 / \mathrm{ie} 50477 \mathrm{a} 033$.

[17] Nijemeisland, M. and Dixon, A. G., "Comparison of CFD simulations to experiment for convective heat transfer in a gas-solid fixed bed," Chem. Engg. J., vol. 82 , pp. 231-246, 2001. DOI: 10.1016/S13858947(00)00360-0.

[18] Dixon, A. G. and Cresswell, D. L., "Estimation of heat-transfer parameters in packed-beds from radial temperature profiles - Comment," Chem. Engg. J. Bioch Engg., vol. 17, pp. 247-248, 1979.

[19] Gladden, L. F., "Recent advances in MRI studies of chemical reactors: Ultrafast imaging of multiphase flows," Top Catal., vol. 24, pp. 19-28, 2003. DOI: 10.1023/B:TOCA.0000003072.56070.2e.

[20] Masoumi, M. E., Sadrameli, S. M., Towfighi, J. and Niaei. A., "Simulation, optimisation and control of a thermal cracking furnace," Energy, vol. 31, pp. 516$527,2006$.

[21] Gladden, L. F., Mantle, M. D. Sederman, A. J. and Yuen, E.H.L., "Magnetic resonance imaging of singleand two-phase flow in fixed-bed reactors," Appl. Magn. Reson., vol. 22, pp. 201-212, 2002. DOI: 10.1007/BF03166103.

[22] Ziolkowska, I. and Ziolkowski, D., "Modelling of gas interstitial velocity radial distribution over crosssection of a tube packed with granular catalyst bed; effects of granule shape and of lateral gas mixing," Chem. Engg. Sci., vol. 62, pp. 2491-2502, 2007. DOI: 10.1016/j.ces.2007.01.029.

[23] Logtenberg, S. A. and Dixon, A. G., "Computational fluid dynamics studies of fixed bed heat transfer," Chem. Engg. Process, vol. 37, pp. 7-21, 1998. DOI: 10.1016/S0255-2701(97)00032-9.

[24] Dixon, A. G., Nijemeisland, M. and Stitt, E. H., "CFD study of heat transfer near and at the wall of a fixed bed reactor tube: Effect of wall conduction," Ind. Engg. Chem. Res., vol. 44, pp. 6342-6353, 2005. DOI: 10.1021/ie049183e

[25] Taskin, M. E., Dixon, A. G. and Stitt, E. H., "CFD study of fluid flow and heat transfer in a fixed bed of cylinders," Numer. Heat Transf.-Appl., vol. 52, pp. 203-218, 2007. DOI: 10.1080/10407780601149896.

[26] Nasrin, R. and Alim, M. A., "Semi-empirical relation for forced convective analysis through a solar 
collector," Solar Energy, vol. 105, pp. 455-467, 2014. DOI: 10.1016/j.solener.2014.03.035.

[27] Mabood, F., Ibrahim, S. M., Rashidi, M. M., Shadloo, M. S., and Lorenzini, G., "Non-uniform heat source/sink and soret effects on MHD non- Darcian convective flow past a stretching sheet in a micropolar fluid with radiation," Int. J. of Heat and Mass Transf., vol. 93, pp. 674-682, 2016. DOI: 10.1016/j.ijheatmasstransfer.2015.10.014.

[28] Zienkiewicz, O. C. and Taylor, R. L., "The finite element method," Fourth Ed., McGraw-Hill, 1991.

\section{NOMENCLATURE}

Pre-exponential factor

$c$

Dimensional concentration of fluid $\left(\mathrm{kgl}^{-1}\right)$

C

$C_{p}$

$E_{a}$

$k$

$L$

$H$

$m$

$\mathrm{Nu}$

$p$

$P e$

$\begin{array}{ll}P r & \text { Prandtl number } \\ R & \text { Rate of chemical reaction }\left(\mathrm{mol} \mathrm{m}^{-3} \mathrm{~s}^{-1}\right) \\ R e & \text { Reynolds number } \\ S h & \text { Mean Sherwood number } \\ T & \text { Fluid temperature }(\mathrm{K}) \\ v_{r} & \text { Velocity in } r \text {-direction }\left(\mathrm{ms}^{-1}\right) \\ v_{z} & \text { Velocity in } z \text {-direction }\left(\mathrm{ms}^{-1}\right) \\ \mathrm{V} & \text { Magnitude of mean velocity } \\ \bar{V} & \text { Volume of reactor }\left(\mathrm{m}^{3}\right)\end{array}$

\section{Greek symbols}

$\begin{array}{ll}\alpha & \text { Thermal diffusivity }\left(\mathrm{m}^{2} \mathrm{~s}^{-1}\right) \\ \theta & \text { Dimensionless fluid temperature } \\ \mu & \text { Dynamic viscosity of the fluid }\left(\mathrm{m}^{2} \mathrm{~s}^{-1}\right) \\ v & \text { Kinematic viscosity of the fluid }\left(\mathrm{m}^{2} \mathrm{~s}^{-1}\right) \\ \rho & \text { Density of the fluid }\left(\mathrm{kgm}^{-3}\right) \\ \Delta & \text { Increment }\end{array}$

\section{Subscripts}

$\begin{array}{ll}a v & \text { average } \\ h & \text { heated } \\ \text { in } & \text { input }\end{array}$

